\title{
INTRODUCTION
}

\section{Anti-IgE: changing lives in clinical practice?}

\author{
S.T. Holgate
}

$\triangle$ s physicians, we frequently encounter patients with severe persistent asthma who remain symptomatic despite receiving the best available treatment and optimal management efforts. If we are unable to achieve adequate asthma control despite using all available therapeutic options, these patients remain exposed to a high risk of serious exacerbations and asthma-related mortality. Addressing the unmet medical needs of this difficult-to-treat population is one of the greatest challenges in asthma management.

Asthma frequently has an allergic component. Immunoglobulin (Ig)E is central to the pathogenesis of allergic asthma and presents an ideal target for novel therapeutic agents. Omalizumab, the first anti-IgE treatment, suppresses $\operatorname{IgE}$ mediated allergic/inflammatory reactions by binding to free IgE. In clinical studies, add-on omalizumab significantly reduced asthma exacerbation rates and the need for emergency medical interventions, and improved quality of life, in patients with severe persistent allergic asthma who were symptomatic despite taking regular high-dose inhaled corticosteroids and long-acting $\beta_{2}$-adrenoceptor agonists.

I had great pleasure in chairing a Novartissponsored satellite symposium entitled "AntiIgE: changing lives in clinical practice?" at the 16th Annual European Respiratory Society Congress (2006) held in Munich, Germany. The symposium provided an opportunity to bring together a distinguished faculty of experts in the field to discuss the role of anti-IgE therapy in addressing the unmet needs of patients with severe and poorly controlled asthma. In the symposium, we discussed the central role of $\operatorname{IgE}$ in the allergic/inflammatory cascade, the rationale for anti-IgE therapy, and the latest evidence regarding the efficacy and safety of omalizumab when used to treat inadequately controlled severe persistent allergic asthma. The important issues of patient selection and evaluation of treatment response to omalizumab were also covered. The proceedings of this important and timely symposium are reported in the present issue of the European Respiratory Review.
In the first paper of the present issue, HAMELMANN [1] provides an overview of the central role of $\operatorname{IgE}$ in the allergic asthma inflammatory cascade and the mechanism of action of omalizumab. By reducing serum $\operatorname{IgE}$ levels and high-affinity $\operatorname{IgE}$ receptor (FceRI) expression on key cells in the inflammatory cascade, omalizumab blocks the release of inflammatory mediators from mast cells and reduces the subsequent infiltration of inflammatory cells, most notably eosinophils, into the airway. HAMELMANN [1] concludes that "the antiinflammatory effects of omalizumab provide proof-of-concept of the key role played by $\operatorname{IgE}$ in allergic respiratory disease" and that "omalizumab represents a novel approach to the treatment of asthma, inhibiting the inflammatory cascade before it starts."

PARTRIDGE [2] highlights the scale and impact of severe asthma and the need for careful diagnosis. The unmet needs in patients with severe asthma are illustrated by the findings of the Asthma Insights and Reality in Europe (AIRE) study [3], the Fighting for Breath survey [4], the International Asthma Patient Insight Research (INSPIRE) study [5] and the Gaining Optimal Asthma Control (GOAL) study [6]. PARTRIDGe [2] concludes that "despite treatment with currently available therapy, there remains a patient group who have ongoing morbidity, require significant use of health services and are at risk of severe exacerbations" and that "omalizumab may help address the clear and unmet need for an effective and safe treatment of patients with severe persistent allergic asthma who remain symptomatic despite optimised standard treatment."

BuHL [7] reviews the efficacy and safety of omalizumab in clinical trials. Particular focus is given to the Investigation of Omalizumab in Severe Asthma Treatment (INNOVATE) study [8], which enrolled patients with inadequately controlled severe persistent allergic asthma despite high-dose inhaled corticosteroids (ICS) in combination with a long-acting $\beta_{2}$-agonist (LABA) and additional controller medication if required. In the INNOVATE study, add-on omalizumab significantly reduced clinically significant exacerbation rates by $26 \%$ (0.68 versus
CORRESPONDENCE

S.T. Holgate

Southampton General Hospital RCMB Division

Mailpoint 810

Level D

Centre Block

Southampton S016 6YD UK

Fax: 442380701771

E-mail: sth@soton.ac.uk

STATEMENT OF INTEREST

S.T. Holgate has received payment

for chairing an advisory board for

Novartis Pharma AG, has been

reimbursed for attending and

speaking at a conference (AAAAI) in the USA, and is in receipt of a research grant from Novartis Pharma AG. This issue of the European Respiratory Review contains proceedings of a satellite symposium held at the 16th ERS Annual

Congress, 2006, which was sponsored by Novartis Pharma AG The authors were assisted in the preparation of the text by professional medical writers at $\operatorname{ACUMED}_{\mathbb{R}}$; this support was funded by Novartis Pharma AG. 
$0.91 ; p=0.042)$, severe exacerbation rates by $50 \%$ ( 0.24 versus $0.48 ; p=0.002)$ and emergency visit rate by $44 \%$ ( 0.24 versus $0.43 ; p=0.038)$ and significantly improved asthma-related quality of life $(p<0.001)$, compared with placebo [8]. As patients enrolled in the INNOVATE study are the asthma patients with the greatest unmet need, these data are of great clinical importance and are highly encouraging. The results of the INNOVATE study are supported by pooled efficacy analyses [9, 10] and a good safety and tolerability profile [11]. BuHL [7] concludes that "omalizumab addresses an unmet medical need in patients with severe persistent allergic asthma whose symptoms persist despite receiving high-dose ICS and LABA, allowing these patients to live beyond the limitations of their asthma."

In my article [12], evidence showing that there is no reliable way to predict which patients will achieve a greater response to omalizumab is presented [13]. Physicians can easily and reliably identify patients who respond to omalizumab [13]; all patients eligible for omalizumab treatment should receive a 16week trial and treatment, which is to be continued only if the physician judges that a marked improvement in asthma control has been achieved, as specified in the European Union (EU) label. As I point out, identifying responders, and continuing treatment only in these patients, minimises unwarranted drug exposure, whilst treatment benefit and cost-effectiveness of therapy are maximised.

In the final paper of the present issue, BEEH [14] provides specific details on the indication and clinical use of omalizumab. It is important to recognise that the indication for omalizumab varies in different countries. In the EU, omalizumab is indicated as add-on therapy to improve asthma control in adult and adolescent patients ( $\geqslant 12$ yrs of age) with severe persistent allergic (total $\mathrm{IgE} 30-700 \mathrm{IU} \cdot \mathrm{mL}^{-1}$ ) asthma who have a positive skin test or in vitro reactivity to a perennial aeroallergen, and who despite receiving daily high-dose ICS and a LABA have the following characteristics: reduced lung function (forced expiratory volume in one second $<80 \%$ ); frequent daytime symptoms or night-time awakenings; and multiple documented severe asthma exacerbations. Patients who receive omalizumab should be assessed by their physician after 16 weeks and treatment continued only if there has been a marked improvement in asthma control. Omalizumab is administered by subcutaneous injection every 2 or 4 weeks at a dosage determined using a dosing table based on the patient's pre-treatment serum total IgE levels and body weight.

\section{REFERENCES}

1 Hamelmann E. The rationale for treating allergic asthma with anti-IgE. Eur Respir Rev 2007; 16: 61-66.

2 Partridge MR. Examining the unmet need in adults with severe asthma. Eur Respir Rev 2007; 16: 67-72.

3 Rabe KF, Vermeire PA, Soriano JB, Maier WC. Clinical management of asthma in 1999: the Asthma Insights and Reality in Europe (AIRE) study. Eur Respir J 2000; 16: 802-807.

4 European Federation of Allergy and Airways Diseases Patients Associations. Fighting for Breath. www.efanet.org. Date last accessed: October 2006.

5 Partridge MR, van der Molen T, Myrseth SE, Busse WW. Attitudes and actions of asthma patients on regular maintenance therapy: the INSPIRE study. BMC Pulm Med 2006; 6: 13.

6 Bateman ED, Boushey HA, Bousquet J, et al. Can guidelinedefined asthma control be achieved? The Gaining Optimal Asthma ControL study. Am J Respir Crit Care Med 2004; 170: 836-844.

7 Buhl R. Anti-IgE: lessons from clinical trials in patients with severe allergic asthma symptomatic despite optimised therapy. Eur Respir Rev 2007; 16: 73-77.

8 Humbert M, Beasley R, Ayres J, et al. Benefits of omalizumab as add-on therapy in patients with severe persistent asthma who are inadequately controlled despite best available therapy (GINA 2002 step 4 treatment): INNOVATE. Allergy 2005; 60: 309-316.

9 Bousquet J, Cabrera P, Berkman N, et al. The effect of treatment with omalizumab, an anti-IgE antibody, on asthma exacerbations and emergency medical visits in patients with severe persistent asthma. Allergy 2005; 60: 302-308.

10 Chipps B, Buhl R, Beeh K-M, Fox H, Thomas K, Reisner C. Improvement in quality of life with omalizumab in patients with severe allergic asthma. Curr Med Res Opin 2006; 22: 2201-2208.

11 Corren J, Casale T, Lanier BQ, Blogg M, Reisner C, Gupta N. Omalizumab is well tolerated in adolescent/ adult patients ( $\geqslant 12$ years) with moderate-to-severe persistent asthma. J Allergy Clin Immunol 2005; 115: S75.

12 Holgate ST. How to evaluate a patient's response to antiIgE. Eur Respir Rev 2007; 16: 78-84.

13 Bousquet J, Rabe K, Humbert M, et al. Predicting and evaluating response to omalizumab in patients with severe allergic asthma. Respir Med 2007; 101: 1483-1492.

14 Beeh K-M. Which patients should be treated with anti-IgE? Eur Respir Rev 2007; 16: 85-87. 